\title{
Therapeutic amnioinfusion in oligohydramnios during pregnancy (excluding labor)
}

\author{
Mahvish Qazi ${ }^{1}$, Najmus Saqib ${ }^{2 *}$, Abida Ahmed ${ }^{1}$, Imran Wagay ${ }^{3}$
}

\begin{abstract}
${ }^{1}$ Department of Obstetrics and Gynecology, SKIMS Soura Srinagar Kashmir, India
${ }^{2}$ Department of Paediatrics and Neonatology, Government Medical College Jammu, Jammu and Kashmir, India

${ }^{3}$ Department of Radiodiagnosis, Govt. Medical College Srinagar, Jammu and Kashmir, India
\end{abstract}

Received: 05 August 2017

Accepted: 04 September 2017

\author{
*Correspondence: \\ Dr. Najmus Saqib, \\ E-mail: shstar321@gmail.com
}

Copyright: (c) the author(s), publisher and licensee Medip Academy. This is an open-access article distributed under the terms of the Creative Commons Attribution Non-Commercial License, which permits unrestricted non-commercial use, distribution, and reproduction in any medium, provided the original work is properly cited.

\begin{abstract}
Background: Oligohydramnios is a serious complication of pregnancy that is associated with a poor perinatal outcome and complicates $1-5 \%$ of pregnancies. The purpose of this study was to evaluate the role of antepartum transabdominal amnioinfusion on amniotic fluid volume/latency period in pregnancies with oligohydramnios.

Methods: This study was conducted in the Department of Obstetrics and Gynaecology at Sher-i-Kashmir Institute of Medical Sciences Soura Srinagar. In this study, a total of 54 pregnant women with ultrasonographically diagnosed oligohydramnios i.e. AFI $<5 \mathrm{~cm}$ and gestational age of $>24$ weeks were taken for therapeutic amnioinfusion and its effects on amniotic fluid volume were studied. Statistical Software SPSS (Version 20.0) and Microsoft excel were used to carry out the statistical analysis of data. P-value less than 0.05 was considered statistically significant.

Results: Mean age of patients in our study was 27.5 \pm 3.19 years and gestational age group of $28-34$ weeks. The mean AFI pre and post amnioinfusion was found to be $3.3 \mathrm{~cm}$ and $8.8 \mathrm{~cm}$ respectively. The difference was found to be statistically significant with a $\mathrm{p}$ value of $<0.001$. There was increase in the latency period in the studied patients with a mean latency period of $42.8 \pm 14.94$ days. Mean number of transabdominal amnioinfusions in our study was $1.48 \pm 0.64$. In our study, majority of patients i.e. $33(61.1 \%)$ delivered at $38-40$ weeks with a mean age at delivery $37.4 \pm 1.92$ weeks. In our study, maximum number of patients i.e. $32(59.3 \%)$ were delivered by full term normal delivery and only $15(27.8 \%)$ required caesarean section. $78 \%$ of newborns weighed $>2.5 \mathrm{~kg}$. The mean weight of newborn was $2.9 \pm 0.59 \mathrm{kgs}$. The incidence of newborn admissions to NICU was $20.4 \%$. Number of neonatal deaths in our study was $5.6 \%$. There was reduction of neonatal admission to NICU and neonatal deaths after transabdominal amnioinfusion.

Conclusions: Antepartum transabdominal amnioinfusion is a useful procedure to reduce complications resulting from decreased intra-amniotic volume. It significantly raises the amniotic fluid especially useful in preterm pregnancies, where the procedure allows for a better perinatal outcome by significantly prolonging the duration of pregnancy, increasing birth weight, preventing fetal distress and thereby reducing operative intervention. Optimizing the selection of patients who are good candidates for the procedure is a prerequisite.
\end{abstract}

Keywords: Amnioinfusion, Oligohydramnios, Pregnancy

\section{INTRODUCTION}

Amniotic fluid surrounds the fetus in intrauterine life providing a protected, low resistance space suitable for fetal movements, growth and development. Disturbance of the balance between amniotic fluid production and consumption leads to oligo or polyhydramnios, both of which are associated with poor perinatal outcome related to the degree of fluid volume change. ${ }^{1}$ Oligohydramnios is a serious complication of pregnancy that is associated 
with a poor perinatal outcome. It complicates $1-5 \%$ of term pregnancies. $^{2}$ Overall incidence is $3.9 \%$ of all pregnancies. Oligohydramnios is technically defined as amniotic fluid index less than fifth percentile for gestational age. $^{3}$

\section{It has been described sonographically as}

- Amniotic fluid volume less than $500 \mathrm{ml}$ at 32-36 weeks of gestation. ${ }^{4}$

- Diminished or less than $200 \mathrm{ml}$ at term. ${ }^{1}$

- When the maximum vertical pool of liquor is less than $2 \mathrm{~cm}^{5}$

- Amniotic fluid index less than $5 \mathrm{~cm} .{ }^{6}$

Borderline Oligohydramnios is defined as amniotic fluid index between $5.1-8 \mathrm{~cm}$. Normal amniotic fluid index is between $8.1-20 \mathrm{~cm}$.

\section{Causes of Oligohydramnios}

- Maternal causes are: Uteroplacental insufficiency, Hypertension, Diabetes, Preeclampsia, Hypovolumia, Elevated $2^{\text {nd }}$ trimester alpha fetoprotein

- Placental causes are: Abruption, Twin-twin transfusion syndrome

- Fetal causes are: Chromosomal abnormalities Congenital anomalies like:

- A. Renal anomalies: Renal agenesis, Urethral obstruction, Prune-belly syndrome, Bilateral multicystic kidneys

- B. Non-renal: Triploidy, Thyroid gland agenesis, Thanatophoric dwarfism, Skeletal dysplasia, IUGR, Post term pregnancy, Ruptured membranes, Intrauterine death

- Drugs: Prostaglandin synthetase inhibitors, Angiotensin converting enzyme inhibitors

- Idiopathic.

\section{Diagnosis}

\section{Diagnosis by Obstetrical examination}

- Height of the uterus is less than the period of gestation.

- Fetal parts are easily felt because of scanty liquor.

- Malpresentations are more common.

- There may be evidence of associated fetal IUGR.

\section{Diagnosis by ultrasound}

Ultrasound shows fetal growth, the structure of the kidneys and urinary tract, and detect urine in the fetal bladder. Doppler flow may be used to check the arteries in the kidneys to rule out renal causes of oligohydramnios.
The Ultrasound Techniques currently used for the evaluation of amniotic fluid include.

- Subjective assessment

- Maximum vertical pocket/Single deepest vertical pocket

- Amniotic fluid index

- Dye dilution technique

- Two diameter amniotic fluid pocket

\section{Management}

Oligohydramnios may be managed

- Expectantly by

- a. Fetal surveillance and/or regular ultrasound assessment of amniotic fluid volume.

- b. Nutrients with multivitamins e.g. - Zinc, Selenium.

- Actively by

- a. Induction of labour

- b. Maternal hydration

- c. Furosemide

- d. Amino acid infusion

- e. Amnioinfusion.

\section{Amnioinfusion}

Amnioinfusion is the instillation of normal saline or lactated Ringer's solution into the amniotic sac to correct oligohydramnios. It has been proven to be safe and effective. It can be prophylactic, diagnostic, or therapeutic. Two techniques are used for amnioinfusion

- Transabdominal

- Transvaginal

\section{Antepartum Transabdominal amnioinfusion ${ }^{7}$}

It is a useful procedure to reduce complications resulting from decreased intra-amniotic volume. It is especially useful in preterm pregnancies, where the procedure allows for a better perinatal outcome by prolonging the duration of pregnancy. It is a safe, effective option for the prevention of fetal distress in pregnancies with oligohydramnios. In patients with severe oligohydramnios it definitely helps in making certain diagnosis and better prediction of fetal outcome.

\section{METHODS}

This study was conducted in the Department of Obstetrics and Gynaecology at Sher-i-Kashmir Institute of Medical Sciences Soura Srinagar during the study period between 1st August 2014 and 29 ${ }^{\text {th }}$ February 2016, after obtaining clearance from the institutional ethical committee.

A total of 54 pregnant women with clinically suspected and ultrasonographicaly documented oligohydramnios with gestational age group $>24$ weeks were recruited in 
the study. A written informed consent was taken. Eligibility was determined by inclusion and exclusion criteria.

\section{Inclusion criteria}

Maternal age ranging between 20-38 years and parity of 1-4. Singleton pregnancy with cephalic presentation. At least 2 ultrasound examinations for gestational age confirmation and confirmation of oligohydramnios. Patients with reactive cardiotocography (CTG) test, amniotic fluid index $<5 \mathrm{~cm}$, having intact membranes. Pregnancy of 24 weeks onwards excluding labour. Written informed consent.

\section{Exclusion criteria}

Pregnancy complicated by obstetrical, medical and surgical disorders. Patient in labour at the time of admission or who had been given cervical circlage. Patients with chorioamnionitis or with ruptured membranes. Fetal congenital anomalies detected at prenatal ultrasonography, or fetal chromosomal abnormalities. Fetal condition mandating immediate delivery. Undiagnosed third trimester bleeding. Patients with Human immunodeficiency virus (HIV), hepatitis B virus (HBV) and hepatitis $\mathrm{C}$ virus (HCV) infection and other infections. Patients with multiple gestation or previous caesarean section. Presence of placental anomalies. Pregnancy of $<24$ and $>36$ weeks gestational age. Lack of consent. Maternal and fetal confounding factors. Patients with placenta previa or with malpresentation

The objective of the study was to study the effect of antepartum transabdominal amnioinfusion on amniotic fluid volume and latency period in pregnancies with oligohydramnios.

In all pregnant women who were recruited for this study, a baseline ultrasonographic scan was performed, a colour Doppler was done for fetal biometry, morphological evaluation and for amniotic fluid assessment using the AFI (amniotic fluid index) with the four-quadrant technique. ${ }^{6}$ Oligohyrdamnios was diagnosed when AFI was $<5 \mathrm{~cm}$. Diagnosed cases of oligohydramnios were selected for ultrasonographic guided transabdominal amnioinfusion.

A CTG (cardiotocograph) was done and gestational age was confirmed by asking menstrual history, LMP (last menstrual period), clinical examination and by ultrasonography. All patients were counselled extensively including possible benefits and risks of the procedure. A detailed history and complete physical examination was done. At presentation, all women were examined to exclude a diagnosis of PROM (premature rupture of membranes). This was confirmed by taking a proper history i.e. any history of leaking and on sterile speculum examination, observing pooling of amniotic fluid in the vagina. Anti-D prophylaxis (Inj. Rhoclone 300 $\mu \mathrm{g}$ intramuscularly; monoclonal anti-Rho (D) gamma globulin) was given in all $\mathrm{Rh}$ negative pregnant women. Procedure of transabdominal amnioinfusion was done in all eligible cases.

Amniotic fluid index (AFI) was determined at the end of the procedure and a detailed ultrasound was repeated to check for fetal well-being. The AFI was repeated after 30 minutes following the procedure followed by after 24 hours and once weekly by four quadrant techniques. If repeat AFI was $<5 \mathrm{cms}$ and/or median deepest amniotic fluid pocket was $<2 \mathrm{~cm}$ and persisted for four days, we decided to repeat amnioinfusion weekly. Amnioinfusion was deemed successful if the median deepest pocket of fluid was $>2 \mathrm{~cm}$ after 48 hours of procedure and was maintained at $>2 \mathrm{~cm}$ during the latency period. After the procedure, the perineum was checked for any fluid loss indicating PROM (Premature rupture of membranes).

All women received antibiotic therapy (Inj. Ceftriaxone $1 \mathrm{~g}$ intravenously twice a day) and tocolytics (Tablet Isoxuprine $40 \mathrm{mg}$ once a day) for 5 days following the procedure, and all patients were monitored carefully clinically, by ultrasound and by daily CTG. The pregnant women in whom amnioinfusion was successful were followed weekly in the OPD where the AFI was remeasured to assess the need for further infusions. Repeat amnioinfusion was carried out when the AFI measurement fell below the value achieved at the end of first infusion.

Delivery was considered to be expedited in the presence of clinical chorioamnionitis, fetal tachycardia with diminished variability, recurrent late or severe variable decelerations, biophysical profile score $<6$, or abruptio placentae. Women were allowed to deliver vaginally unless there were maternal or obstetric indications for caesarean section. Overall management was based on patient preference, parity, ongoing pregnancy being assessed clinically, sonographically and by NST (Nonstress test), onset of labour and maternal condition.

\section{Statistical methods}

Statistical Software SPSS (Version 20.0) and Microsoft excel were used to carry out the statistical analysis of data. Descriptive Statistics of data including the mean and standard deviation for numerical variables and the percentages of different categories for categorical variables was obtained. Frequency distribution tables, bar and pie charts were used for data presentation. P-value less than 0.05 was considered statistically significant.

\section{RESULTS}

In present study, we enrolled a total of 54 pregnant women with ultrasonographically diagnosed oligohydramnios i.e. AFI $<5 \mathrm{~cm}$ and gestational age of $>24$ weeks. All patients who were selected for the study, 
cooperated to participate and there were no drop outs from the study. The aim of our study was to determine the usefulness of antepartum transabdominal amnioinfusion on AFI and its role in prolonging latency period. Transabdominal amnioinfusion was performed and results were analysed.

Table 1: Mean AFI (cm) pre and post infusion in studied patients.

\begin{tabular}{|llll|}
\hline AFI & Mean & SD & P-value \\
\hline Pre-infusion & 3.3 & 0.86 & \multirow{2}{*}{$<0.001^{*}$} \\
\hline Post-infusion & 8.8 & 1.30 & \\
\hline
\end{tabular}

Table 1 shows mean AFI $(\mathrm{cm})$ pre and Post Infusion in studied patients. The mean AFI before and after intervention was $3.3 \mathrm{~cm}$ and $8.8 \mathrm{~cm}$ respectively, the difference was statistically significant with $\mathrm{p}$ value of $<0.001$.

Table 2: Showing increase in latency period in studied patients.

\begin{tabular}{|c|c|c|c|c|}
\hline $\begin{array}{l}\text { Increase in } \\
\text { Latency } \\
\text { Period (Days) }\end{array}$ & $\begin{array}{l}\text { No. of } \\
\text { patients }\end{array}$ & $\%$ & Mean \pm SD & Range \\
\hline$<15$ & 3 & 5.6 & \multirow{5}{*}{$42.8 \pm 14.94$} & \multirow{5}{*}{$2-74$} \\
\hline $15-29$ & 8 & 14.8 & & \\
\hline $30-44$ & 14 & 25.9 & & \\
\hline $45-59$ & 25 & 46.3 & & \\
\hline $60-74$ & 4 & 7.4 & & \\
\hline
\end{tabular}

Table 2 shows increase in latency period (duration between time of presentation and time of delivery) in our study with majority of patients $25(46.3 \%)$ with $45-59$ days of increased latency period and only $3(5.6 \%)$ patients had $<15$ days latency period. Mean Latency period was $42.8 \pm 14.94$ days.

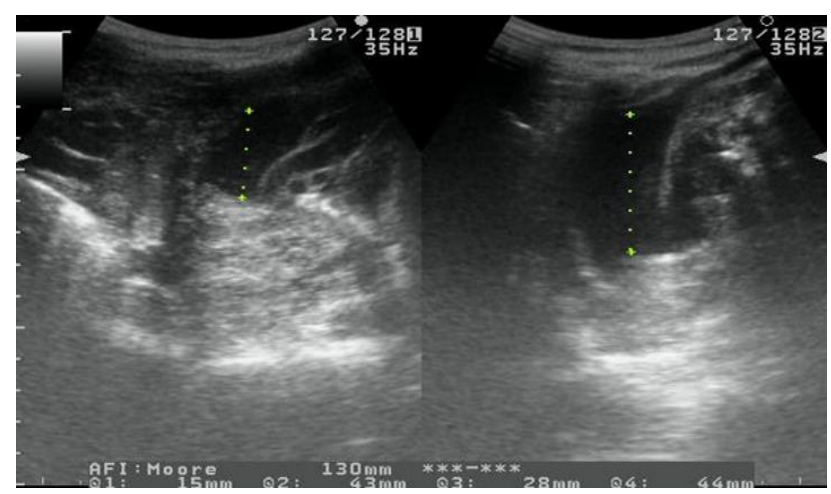

Figure 1: AFI before and after amnioinfusion.

Mean age of patients in our study was $27.5 \pm 3.19$ years and gestational age group of 28-34 weeks. The mean AFI pre and post amnioinfusion was found to be $3.3 \mathrm{~cm}$ and $8.8 \mathrm{~cm}$ respectively. The difference was found to be statistically significant with a $p$ value of $<0.001$. In our study, majority of pregnant women were primigravida and patients were studied on the basis of obstetric index like, gravidity, parity and no. of previous abortions. In present study, there was increase in the latency period in the studied patients with a mean latency period of $42.8 \pm 14.94$ days. Mean number of transabdominal amnioinfusions in our study was $1.48 \pm 0.64$. In our study, majority of patients i.e. $33(61.1 \%)$ delivered at $38-40$ weeks with a mean age at delivery $37.4 \pm 1.92$ weeks. In our study, maximum number of patients i.e. $32(59.3 \%)$ were delivered by full term normal delivery and only 15 $(27.8 \%)$ required caesarean section.

The mean apgar score in our study at 1 and 5 minutes was $6.8 \pm 1.09$ and $8.3 \pm 0.87$ respectively. $78 \%$ of newborns weighed $>2.5 \mathrm{~kg}$. The mean weight of newborn was $2.9 \pm 0.59 \mathrm{kgs}$. The incidence of newborn admissions to NICU was $20.4 \%$. Number of neonatal deaths in our study was $5.6 \%$. There was reduction of neonatal admission to NICU and neonatal deaths after transabdominal amnioinfusion.

\section{DISCUSSION}

Oligohydramnios complicates $1-5 \%$ of pregnancies. It leads to various fetal and maternal complications. Fetal complications like: cord compression and fetal distress, fetal pulmonary hypoplasia and stillbirth, fetal growth restriction, low Apgar score, NICU admission and fetal mortality.

Maternal complications like: Prolonged labour due to inertia, induction of labour, increased incidence of operative intervention due to malpresentations and its associated morbidity and mortality.

Oligohydramnios poses not only a diagnostic challenge but also a dilemma of management for the obstetrician. The general outcome is usually poor, no matter, whatever is the cause of oligohydramnios. The purpose of our study was to determine the usefulness of antepartum transabdominal amnioinfusion in reducing the perinatal ill effects of oligohydramnios and effect of amnioinfusion on various parameters like amniotic fluid volume (AFV), latency period, need for operative intervention, and reduction in associated complications, perinatal morbidity and mortality.

In our study, the pregnant women were between 28-34 weeks of gestation which was very similar to the gestational age group of various previous studies like Turhan NO, Atacan $\mathrm{N}$ et al who included pregnancies between 23 and 35 weeks of gestation. ${ }^{8}$ Gowri R, Soundaraghavan $\mathrm{S}$ et al included singleton pregnancies from 24-34 weeks of gestation. ${ }^{9}$

In present study, patients with amniotic fluid index of $\leq$ $5 \mathrm{cms}$ were included, mean AFI in cms was $3.3 \pm 0.86$ which was similar to previous studies conducted by Anshuja Singla et al, Dotunogunyemi et al, Kim et al, 
Jung $\mathrm{SH}$, et al and Gowri $\mathrm{R}$ et al also included patients with AFI of $<5 \mathrm{~cm} .^{10-13,9}$

In present study, the mean amniotic fluid index pre and post transabdominal amnioinfusion was $3.3 \mathrm{~cm}$ and 8.8 $\mathrm{cm}$ respectively with $\mathrm{p}$ value $<0.001$ which is statistically significant. These readings were almost similar to those observed by previous workers like Kim GJ et al, observed pre and post infusion amniotic fluid index as $4 \mathrm{~cm}$ and 9.3 cm respectively. ${ }^{12}$ Dotunogunyemi et al, observed pre and post infusion amniotic fluid index as $1.1 \mathrm{~cm}$ and $12 \mathrm{~cm}$ respectively. ${ }^{11}$ Turhan et al noted amniotic fluid index of $6 \mathrm{~cm}$ and $11 \mathrm{~cm}$ pre and post infusion respectively. ${ }^{8} \mathrm{Jung}$ et al, R Gowri et al, also observed a significant increase in amniotic fluid index following transabdominal amnioinfusion and thereby reduces the complications arising from oligohydramnios. ${ }^{13,9}$

Mean number of infusions in our study was $1.48 \pm 0.64$ in each pregnant women. In the study conducted by Fatima $\mathrm{T}$ Butt et al, mean number of infusions was 1.05 per pregnant women. ${ }^{14}$

In present study, there was a significant increase in latency period in patients in whom TAA was performed. Mean Latency period was $42.8 \pm 14.94$ days. Turhan et al, reported a significant increase in latency period in patients in whom TAA was performed. ${ }^{8}$ The authors concluded that transabdominal amnioinfusion prolongs the latency period and improves perinatal outcome in preterm pregnancies complicated by oligohydramnios. Similarly Locatelli et al, Jung et al, Fatima T Butt et al and GJ Kim et al, also noted a significant increase in latency period. ${ }^{12-15}$

In our study, $27.8 \%$ of patients needed caesarean section which was comparable to various studies like Patrizia Vergani et al calculated rate of LSCS 5\% in study group and Chhabra et al calculated rate of LSCS $18 \%$ in the study group. ${ }^{16,17}$ Similarly Mandelbrot et al also reported a significant decrease in rate of caesarean sections in the amnioinfused group. ${ }^{18}$

In our study, the mean APGAR score in study group at 1 and 5 minutes was $6.8 \pm 1.09$ and $8.3 \pm 0.87$ respectively. Kim et al, evaluated mean APGAR score at 1 and 5 minutes in the study group as high as 7.6 and 8.9 which was quite close to our observation. ${ }^{12}$ In our study $78 \%$ of newborns weighed $>2.5 \mathrm{~kg}$. The mean weight of newborns in our study was $2.9 \pm 0.59 \mathrm{~kg}$. Kim et al, observed mean birth weight of $2.6 \mathrm{~kg}$ in study group which is same as in our study. ${ }^{12}$ Locatelli A, Vergani P, et al and Marco De Santis et al also reported a significant increase in birth weight in the amnioinfused group. ${ }^{15,19}$

In present study, the incidence of newborn admissions to neonatal ICU was $20.4 \%$. Anshuja Singla et al reported a significant improvement in the neonatal survival in study group. ${ }^{20}$ TAA reduced significantly early neonatal sepsis in the treatment group and thereby reducing the NICU admissions of the newborns

In present study number of neonatal deaths was $5.6 \%$ (3 babies). One baby died with septicaemia with DIC (Disseminated intravascular coagulopathy) with RDS (Respiratory distress syndrome). Second baby died of septicaemia with DIC with pulmonary haemorrhage. Third baby died of ventilator associated pneumonia with sepsis. Similar findings were noted by Chhabra et al $4 \%$ neonatal deaths in study group. ${ }^{17}$ Gramellini D et al also noted $(5 \%)$ and Anshuja Singla et al (17\%) neonatal deaths. $^{20}$

There were no reported pulmonary, neurological or other sequelae of oligohydramnios in the neonates at birth and in the follow up period.

\section{CONCLUSION}

Antepartum transabdominal amnioinfusion is a useful procedure to reduce complications resulting from decreased intra-amniotic volume. It significantly raises the amniotic fluid index.

It is especially useful in preterm pregnancies, where the procedure allows for a better perinatal outcome by significantly prolonging the duration of pregnancy and by increasing birth weight.

Antepartum transabdominal amnioinfusion is a simple, safe, inexpensive and effective option for the prevention of fetal distress in pregnancies with oligohydramnios and thereby reducing operative intervention. It is a useful therapeutic modality for the reduction of fetal morbidity and mortality. Optimizing the selection of patients who are good candidates for the procedure is a prerequisite.

Funding: No funding sources

Conflict of interest: None declared

Ethical approval: The study was approved by the Institutional Ethics Committee

\section{REFERENCES}

1. Chemberlan MB, Manning FA, Morreson L. Ultrasound evaluation of amniotic fluid II. The relationship of increased amniotic fluid volume to perinatal outcome. Am J Obstet Gynecol. 1984;150: $250-4$

2. Taylor MF, Fisk NM. Hydramnios and oligohydramnios. In James DK, Steer PJ, Weiner CP, Gonik B, editors. High risk pregnancy, $3^{\text {rd }}$ edition. Philadelphia: WB Saunder publications. 2006;27885.

3. Moore TR, Cayle JE. The amniotic fluid index in normal human pregnancy. Am J Obstet Gynecol. 1990;162:1168-73. 
4. Chamberlain PF, Manning FA, Morrison I. Ultrasound evaluation of amniotic fluid volume. Am J Obstet Gynecol. 1984;150:245-9.

5. Manning FA, Harman CR, Morrison I, Menticoglou SM, Lange IR, Johnson JM. Fetal assessment based on fetal biophysical profile scoring IV. An analysis of perinatal morbidity and mortality. Am J Obstet Gynecol. 1990;162(3):703-9.

6. Phelan JP, Smith CV, Small M. Amniotic fluid volume assessment with the 4 quadrant technique at 36-42 week gestation. J Reprod Med. 1987;32:540-2.

7. Vergani P, Ceruti P, Strobelt N, Locatelli A, D'Oria $\mathrm{P}$, Mariani S. Transabdominal amnioinfusion in oligohydramnios at term before induction of labor with intact membranes: a randomized clinical trial. Am-J-Obstet-Gynecol. 1996;175(2):465-70.

8. Turhan NO, Atacan N. Antepartum prophylactic transabdominal amnioinfusion in preterm pregnancies complicated by oligohydramnios. Internat J Gynecol Obstetr. 2002;76(1):15-21.

9. Gowri R, Soundaraghavan S. Evaluation of transabdominal amnio-infusion in the antepartum management of oligohydramnios, complicating preterm pregnancies. J Obstetr Gynaecol India. 2004; 54(5):460-3.

10. Singla A, Yadav P, Vaid NB, Suneja A, Mohammad Faridi MA. Transabdominal amnioinfusion in preterm premature rupture of membranes. Internat $\mathbf{J}$ Gynecol Obstet. 2010;108:199-202.

11. Ogunyemia D, Thompson W. A case controlled study of serial transabdominal amnioinfusions in the management of second trimester oligohydramnios due to premature rupture of membranes. European J Obstetr Gynecol Reproduct Biol. 2002;102:167-72.

12. Kim GJ, Kim SY and Son MS. Pregnancy outcome following amnioinfusion in oligohydramnios. Ultrasound Obstet Gynecol. 2001;18(Suppl.1):32-61.

13. Jung SH, Han JY, Choi EH, Sung SJ, Jo JH, An HG, et al. Fetal outcome following transabdominal amnioinfusion in various causes of oligohydramnios. Korean J Obstet Gynecol. 2001;44(1):80-4.

14. Butt FT, Ahmed BS. The role of antepartum transabdominal amnioinfusion in the management of oligohydramnios in pregnancy. J Matern Fetal Neonatal Med. 2011;24(3):453-7.

15. Locatelli A, Vergani P, Di Pirro G, Doria V, Biffi A, Ghidini A. Role of amnioinfusion in the management of premature rupture of the membranes at $<26$ weeks' gestation. Am J Obstet Gynecol. 2000;183(4):878-82.

16. Vergani P, Ceruti P, Strobelt N, Locatelli A, D'Oria $\mathrm{P}$, Mariani S. Transabdominal amnioinfusion in oligohydramnios at term before induction of labor with intact membranes: a randomized clinical trial. Am J Obstet Gynecol. 1996;175(2):465-70.

17. Chhabra S, Dargan R, Nasare M. Antepartum transabdominal amnioinfusion. International $\mathrm{J}$ Gynecol Obstetr. 2007;97:95-9.

18. Mandelbrot L, Verspyck E, Dommergues M, Breast G. Transabdominal amnioinfusion for the management of non-laboring post-dates with severe oligohydramnios. Fetal Diagn Ther. 1993;8:412-7.

19. Santis MD, Scavo M, Noia G, Masini L, Piersigilli F, Romagnoli C, Carusa A. Transabdominal amnioinfusion treatment of severe oligo- hydramnios in preterm premature rupture of membranes at $<26$ gestational weeks. Fetal Diagn Ther. 2003;18:412-7.

20. Gramellini DD, Piantelli GG, Chiaie LLD, Rutolo SS and Vadora EE. Amnioinfusion in the management of oligohydramnios. J Perinat Med. 1998;26(4):293-301.

Cite this article as: Qazi M, Saqib N, Ahmed A, Wagay I. Therapeutic amnioinfusion in oligohydramnios during pregnancy (excluding labor). Int J Reprod Contracept Obstet Gynecol 2017;6: 4577-82. 